\title{
Argumentation in Discourse: A Socio-discursive Approach to Arguments
}

\author{
Ruth Amossy
}

\author{
H. Glasberg Chair for French Culture \\ Analyse du Discours, Argumentation, Rhétorique (ADARR), \\ Tel-Aviv University \\ Israel \\ amossy@attglobal.net
}

\begin{abstract}
Rather than the art of putting forward logically valid arguments leading to Truth, argumentation is here viewed as the use of verbal means ensuring an agreement on what can be considered reasonable by a given group, on a more or less controversial matter. What is acceptable and plausible is always coconstructed by subjects engaging in verbal interaction. It is the dynamism of this exchange, realized not only in natural language, but also in a specific cultural framework, that has to be accounted for. From this perspective, it is not enough to reconstruct patterns of reasoning. As logos is by definition both Reason and Language, abstract schemata have to be examined in their verbal realization in a given situation of discourse. Such an approach to arguments allows for a "thick" description taking into account their discursive and communicational aspects, as well as argumentation's constitutive dialogism and its inscription in a set of common representations, opinions and beliefs ( $a$ doxa). This approach, exemplified by the analysis of a short text on stock options borrowed from the French newspaper Libération, is an attempt at establishing a dialogue between disciplines like argumentation theories, rhetorical criticism and discourse analysis.
\end{abstract}

Résumé: L'argumentation n'est pas définie ici comme l'art d'avancer des arguments logiquement valides menant à la Vérité, mais comme l'usage de moyens verbaux visant à un accord sur ce qu'un groupe donné peut percevoir comme raisonnable à propos d'un sujet plus ou moins controversé. Ce qui est acceptable et plausible est toujours coconstruit par des sujets qui s'engagent dans une interaction verbale. C'est le dynamisme de cet échange, réalisé non seulement en langue naturelle, mais aussi dans un cadre culturel particulier, qu'il importe de d'éclairer. De ce point de vue, il ne suffit pas de reconstruire des schèmes de raisonnement. Comme le logos est par définition Raison et Langage, les schèmes abstraits doivent être examinés dans leur réalisation verbale, dans une situation de discours donnée. Semblable approche des arguments permet de les décrire dans leur matérialité discursive en tenant compte de leurs aspects communi-cationnels, ainsi que du dialogisme constitutif de l'argumentation et de son inscription dans un ensemble de représentations, opinions et croyances parta-gées (une doxa). Cette approche, exemplifiée par l'analyse d'un bref extrait sur les stock options tiré du journal Libération, constitue une tentative d'établir un dialogue entre des disciplines comme les théories de l'argumentation, la critique rhétorique américaine et l'analyse du discours.

Keywords: Argumentation in discourse, argumentativity, discourse analysis, interdis-course, Perelman, rhetoric

(C) Ruth Amossy. Informal Logic, Vol. 29, No. 3 (2009), pp. 252-267. 


\section{Introduction}

What does an expression like "Argument cultures" actually mean? It may imply that theories of argumentation are culture-dependent and vary according to national settings; it can refer to theories of argumentation taking into account argument's cultural aspects; it can also draw critical attention to cultures privileging arguments and polemics. Exploiting the polysemy of the OSSA 2009 conference's title, I will use all three meanings for the purposes of my own presentation. I will first locate my work in a specific academic argument culture, namely the French one, where argumentation studies have mostly been revived these last decades in the field of linguistics. In so doing, I will also develop a culturedependent conception of argumentation grounded in language considered in its social and institutional dimensions. On a third level, theoretical principles will be exemplified by polemical discourse, a central component of what has been called argument culture, although this notion will here receive a positive twist at odds with its original use by Deborah Tannen.

\section{What is argumentation in discourse?}

My own theory, labeled "argumentation in discourse" (Amossy 2006 [2000]), mainly tries to reconcile argumentation as defined in Perelman's and Olbrechts-Tyteca's New Rhetoric (1958), and the French contemporary tradition of Discourse Analysis (Charaudeau et Maingueneau 2002) ${ }^{1}$. It is important to emphasize at the outset that the latter is not understood as conversational analysis, but as an approach to discourse (especially forms of ordinary written discourse) from both a linguistic and a socio-institutional vantage. Its point of departure is that enunciation (the use of language by a speaking subject) takes place in a formal framework of exchange in which the participants exert a mutual influence on each other (Benveniste 1971). This is the very principle of verbal exchange, be it actual (a dialogue, a debate, a conversation) or virtual (a presidential speech, a newspaper article, a lecture). In any case, a speaker, whether or not she uses the first person, targets an audience, whether present or absent, addressed or non-addressed. The verbal exchange in which she engages always obeys sociodiscursive and institutional constraints varying from culture to

\footnotetext{
${ }^{1}$ In the Anglophone world, the closest equivalent to this approach would be Barbara Johnstone's as elaborated in her excellent textbook Discourse Analysis, and in the recent collective volume Rhetoric in detail attempting to integrate DA and rhetorical analysis (Johnstone \& Eisenhart 2008). I cannot, however, discuss here the differences between the two American and French approaches.
} 
culture: linguistic components, with their multiple internal relations, cannot be cut off from the social dimension of discourse.

When poured into this mould, rhetoric is not without undergoing some modifications. First of all, adherence to a thesis is redefined. The arguer may deliberately try to persuade her addressee in a controversial matter where divergent points of view are clearly expressed, like in a debate or an editorial; but she can also orient ways of looking at things and interpreting the world without putting forward any thesis, like in ordinary conversation or in an information article. In the first case, we can speak of an argumentative goal or objective; in the second case, where there is no explicit intention of persuading, we will speak of the argumentative dimension of discourse (Amossy 2005). In all cases, however, and even when there is no overt controversy, discourse is pervaded by a general argumentativity (Amossy 2009). It always answers some explicit or hidden question, or at least suggests a way of looking at the surrounding world.

My contention is that this argumentativity constitutes an inherent feature of discourse. The argumentative nature of discourse does not imply that formal arguments are used, nor does it mean that a sequential order from premise to conclusion is imposed on the oral or written text. Orienting the way reality is perceived, influencing a point of view and directing behavior are actions performed by a whole range of verbal means. From this perspective, argumentation is fully integrated in the domain of language studies. The analyst has to examine the multiple verbal procedures through which the participants of an exchange try to reach an agreement, to deal with dissent or to influence ways of experiencing the world. How does discourse work to achieve these goals? To raise this question is to consider that argumentation is an aspect of an overall "discursive functioning" that has to be analyzed in its intrinsic logic. This specific functioning has to be accounted for in a descriptive and analytical way. The theory of argumentation in discourse is thus neither prescriptive (as in some classical views on rhetoric) nor evaluative (as in most theories of argumentation, looking for the logical validity of arguments). Moreover, it deals with case studies analyzed in their specific cultural settings rather than with de-contextualized examples aiming at defining universal rules ${ }^{2}$.

In the French field of study in which this theory has developed, it was important to distinguish this fundamentally linguistic view of argumentation from the prevailing trend in language studies, Oswald Ducrot's "argumentation in language" (Anscombre and Ducrot 1988). For Ducrot, argumentation is

\footnotetext{
${ }^{2}$ For a more detailed presentation of French AD, see Maingueneau and Angermüller 2007.
} 
defined as a linking of utterances leading to a conclusion ("it is cold, close the door"), and as such, it is part of the utterance's meaning: meaning is orienting. "You drive too fast" contains in the very use of "too" the conclusion: you'll have an accident. Thus argumentativity is inherent to the structure of language ("la langue" in Saussure's sense) in its pragma-semantic level. It does not belong to discourse (as the use of language by a speaking subject), nor does it pertain to rhetoric as an art of rational persuasion. Ducrot's contention is that the so-called "linguistic argumentation", clearly distinct from "rhetorical argumentation", has nothing to do with $\log o s$ as verbal and rational persuasiontoward which he lately expressed his complete disbelief (Ducrot 2004). Argumentation in discourse theory, on the contrary, sets up to explore discourse as logos: as a way of influencing the other so that an agreement on the reasonable can be looked for, or a dissent managed by verbal means. The social and ethical issues of these two positions are clear and I will not elaborate on them.

\section{Analyzing argumentation from a discursive point of view}

In analyzing argumentation from a discursive point of view, one has to take into account:

1. the situation of discourse with its socio-historical components: it includes (a) the framework of enunciation (who speaks to whom, where and when as reflected in the discourse) and (b) the situation of communication, including so-called contextual elements like the circumstances of the exchange, the selected media, the reputation of the speaker, etc. The situation of discourse thus articulates external and internal elements.

2. the genre of discourse with its pre-established frameworks and constraints

3. the dialogical dimension, or general interdiscursivitythe social discourse circulating at a given moment and the previous texts on which the speaker and/or her audience draw (Bakhtin 1984)

4. the institutional dimension, or the speaker's position(ing) in a specific field (Bourdieu 1991)

Obviously, all these elements are socio-historical and culturedependent. These points raise questions concerning the crucial 
notions of context, agency and argument. Agency and arguments will be examined in more detail in what follows. Let us however say from the outset that the traditional distinction between text and context is here blurred, if not dismissed altogether. Because the situation of communication and the interdiscourse are embedded in the discourse, context is seen as part of the text. Components like the speaker, the addressee, the place and circumstances of the exchange, the generic framework, the discourse that circulates at the time, are all integrated in the text and constitute an integral part of it. This entails that language is taken not only in its formal, but also in its socio-historical and institutional dimensions.

To clarify and illustrate these principles, I will take a brief example borrowed from an article published in the French leftist newspaper Libération by François Sergent, on March 23, 2009. This text participates in a general polemic about bonuses and stockoptions in bailed-out enterprises that took place at that very moment in France (as well as in other countries, including of course the US).

\section{IMPUDENCE}

In the US, it is the AIG bonuses affair that aroused unprecedented indignation in a country rather favorable to economical success. In France, the stockoptions of the Société Générale's four big bosses are rightly causing a scandal. Yes, the bank of Kerviel and of the sub-primes, managed by those little financial geniuses who just granted themselves a few quickly earned millions of euros ${ }^{3}$.

Genre of discourse. The "opinion" article (as opposed to the news article) calls for the development and rational justification of a stance on a controversial matter. It allows for subjectivity and tolerates polemical discourse, defined as a violent confrontation of antagonistic theses. However, it generally imposes some limits on its violence in order to keep the respectability of the paper (especially when the article is signed by one of its chief editors). In

\footnotetext{
${ }^{3}$ Aux Etats-Unis, c'est l'affaire des bonus d'AIG qui a suscité une indignation sans précédent dans un pays plutôt bien disposé envers la réussite économique. En France, ce sont les stock-options des quatre grands chefs de la Société générale qui font justement scandale. Oui, la banque de Kerviel et des subprimes, gérée par ces petits génies de la finance qui viennent de s'octroyer quelques millions d'euros vite gagnés.
} 
the polemical mode of argumentation, the Proponent (the journalist) attacks a target, the Opponent - the SG's executives and all those who support them or do not properly fight their actions. His aim is to discredit the Opponent and his stance through a more or less virulent and passionate denunciation (Kerbrat 1980).

Situation of discourse. On the enunciation level, the speaker, although he does not use the pronoun "I", directly addresses an audience that is not designated but can be reconstructed from the encyclopedic knowledge and from the values presented as selfevident in the text (Amossy 2006). The partners of the exchange are both situated in the present time, with a reference to the immediate past. On the level of the situation of communication, contextual factors have to be clarified. The speaker is the assistant editor of one of the most important French leftist daily papers, Libération, publishing articles both in paper form and on its internet site. Pertaining to the French Left, the speaker is addressing a specific audience generally sharing the same profile, the readers of Libération, and hopefully a larger audience of French citizens. His purpose is to denounce a wrong perpetrated by the main four executives of a huge bank, la Sociéte Générale (SG), who thought it appropriate to take stock-options after a government's bail-out of 1.7 million euros. The article was published on March 21, two days after the big street demonstrations and strikes orchestrated by the French Unions, and one day after Nicolas Sarkozy himself denounced the politics of the bank.

Interdiscourse: The attack launched by the paper is in harmony with the global fight of the French Left against an unregulated and abusive capitalistic system, a stand supposed to be shared by the writer and the audience. Moreover, it echoes a more general popular dissatisfaction with the help provided to banks and big enterprises by the Sarkozy right wing government, and expresses the citizens" anger at the "impudence" of top executives. At the time, the media, the press and multiple blogs were full of reports about the SG's stock-options, and of accusations directed at the bank's executives. The interdiscourse of the article is thus overloaded with reproaches directed at the system and its shameless beneficiaries, as well as with sharp debates over the legitimacy of excessive retributions in a period of severe recession, and over the very principle of top executives' huge retributions.

The institutional framework of the discourse. When broaching the issue, the journalist has to adopt a stance in harmony with the newspaper's declared ideology while occupying and reinforcing his position. In the current state of the field (in Bourdieu's meaning), 
with its structured relationships of financial and symbolic power, the journalist tries to keep a dominant stand not only in relation to right-wing papers dealing with the same topic, but also among other competing left-wing papers (like Le Monde or the weekly Le Nouvel Observateur). Being the editor of a leftist paper, Sergent has to appear as a leading figure of the protest against unruly forms of capitalism and its social abuse, or to find a niche that provides him with some kind of distinct, authoritative position.

\section{The problem of "agency" and the speaker's responsibility}

From this perspective, it appears that strong constraints are imposed on the journalistic discourse. Determined by sociodiscursive and institutional forces, spoken by the social discourse of his time, the writer seems to be left with little room for individual choice and expression. Although situation and genre of discourse are components pertaining to the rhetorical tradition, it seems that in their socio-discursive and institutional version, they contribute to put into question the notion of agency lying at the heart of classical rhetoric. Instead of a context in which the orator makes free individual choices, they appear as a set of preexisting elements conditioning his moves and controlling his "intentions". They impose a framework in which the speaking subject is determined by institutional factors and power relations. Moreover, the text necessarily feeds on interdiscourse - thus echoing the word of the Other and dissolving the free, intentional subject supposed to be fully mastering his meanings.

Does it imply, as Bourdieu (1991) would have it, that the speaking subject is determined by exterior forces and that the power of her speech derives exclusively from her institutional position? Eventually, this would mean that discourse is devoid of power and that there can be no rational reasoning or argumentation aiming at persuasion. Thus Alain Viala (1999), inspired by Bourdieu, claimed that adherence to a thesis is ideological-social groups spontaneously adhere to stances serving their interests and defining their identity. In this framework, the notion of adherence of minds proposed by Perelman as a touchstone of the reasonable threatens to disintegrate. This apparent incompatibility between external and internal agency can, however, find at least a partial solution in the framework of an approach focusing on interaction and co-construction. No doubt, institutional and social constraints frame and model the argumentative exchange. This exchange is however constructed by participants who attempt, with the means that are available in a given cultural framework, to present an opinion or work out a reasonable answer through dialogue. When engaging in discourse, they have to make selections and choose 
orientations, to defend a point of view and to discuss about common problems. Despite constraints, or rather within these constraints, the individual speaker exerts her capacity to adopt a course of action and to act upon the audience. What is more, as the origin of the utterance, she necessarily takes responsibility for her saying, whether deliberately taking a stand or affecting neutrality. Thus, if the power of speech promoted by humanistic rhetoric should not blind us to the social and institutional forces constitutive of the speaker's identity, taking these constraints into consideration does not allow us to deprive speech of power and to dismiss agency altogether. What is more, it should not affect a capital issue often obscured by structuralist and post-structuralist theories: the responsibility of the speaker when using verbal means in a situated exchange.

In this specific case, the article echoes a protest and circulates a discourse widely shared not only by the French left, but also by the dominant French Republican parties, including the Sarkozy government. The journalist is constrained by his position in a leftist newspaper, by his declared political ideology and by his French culture - all of which speak through his voice. All the same, he makes some meaningful choices among the available possibilities. He comforts the protest against the SG's stock-options on moral grounds, without any economical or legal considerations. He thus deliberately joins all the discourses aimed at arousing indignation as a fuel to possible social action (those were the days of the big street demonstrations against the way the government was dealing with the economic crisis). The writer bears entire responsibility for the disposition he tries to create in his audience, as well as for his endeavor to address its moral feelings-indignation implies a notion of injustice and an outcry against a wrong deliberately carried out by an active agent. The journalist could, for instance, have chosen to improve the reader's analytical capacities or engage it in more complex economical considerations about the functions of stock-options. He can also decide to what extent he wants to relate the moral problem to political considerations. The fragment here analyzed being out of context, I should make clear that the ultimate purpose of the article is not simply to arouse angry feelings to be vented in public places, but to call for deeper government involvement in the affairs of a major bank-public anger, the journalist claims, will not calm down until a timely governmental intervention definitely abolishes the privilege of the incriminated executives. Indignant blame is the basis for a constructive move: it leads to an instigation directed at the Sarkozy government, an instigation in which the reader of Libération is called upon to join. In this framework, the journalist as critic and adviser makes choices of social and political consequence for which he is fully accountable. A notion of accountability is thus 
preserved in a theoretical environment where the concept of intentional subject is challenged and revisited.

\section{The inscription of argument schemes in discourse}

In a context where the conception of arguer is reformulated under new auspices, what happens to the notion of argument and to the rhetorical process of agreeing on the reasonable?

The main point here is that argumentation can adopt various shapes obeying the internal logic of a given exchange. Thus formal arguments can be dissimulated under the verbal surface in such a way that their reconstruction becomes a costly and hazardous enterprise. To display underlying argumentative schemes, we sometimes have to entirely dismember and rebuild the text. Moreover, many rhetoricians have emphasized that reduction to logical sets of propositions thwarts the argumentative discourse and overlooks what makes its persuasive force. These lines of criticism point to the importance of alternative forms of persuasion that can supersede logical patterns of arguments. On the other hand, when reading and analyzing a text, we cannot help feeling that reconstructing arguments is important, even if the process is uncertain (the same text can be differently structured by the reader) and incomplete (the reconstructed arguments only partly account for the argumentation imbedded in the text). At the heart of different trends of argumentation theory, including informal logic, reconstruction of arguments underlying the discursive surface cannot but provide a crucial insight into the way discourse actually works and communicates. How is it then possible to reconcile these two orientations - on the one hand, linguistic analysis mainly looking for discursive procedures at the expenses of formal arguments, and on the other hand, logical analysis mainly relying on argument's reconstruction and evaluation at the expenses of the materiality of the text?

Let us go back to our example and start with linguistic analysis. The polemical discourse builds up its case by explicit references to violent feelings, as well as by the use of deprecating terms in the qualification of the target. In order to guarantee the legitimacy of the emotions called for, the journalist first attributes them to others rather than to himself and presents them as unanimous in two whole countries, the US and France. He thus rests his case on a semblance of factuality and a reference to public opinion. However, the axiological adverb "rightly" clearly expresses his moral attitude and his identification with the general feeling of indignation and outrage he is "objectively" evoking. Following the same line of apparent objectivity, "bonuses" and "stock-options" are the grammatical subjects of the verbs and as 
such the agents responsible for the emotional turmoil. Only in a second stage are the grammatical subjects presented as human agents liable to moral condemnation: in order to build its case, the text discloses step by step the true target of the attack, those through whom the scandal arrives, until the writer can express the violent feelings they arouse in him ("Yes, the bank of Kerviel, etc.). The lexical choice of the "four big bosses" instead of the expected "top executives" presents the latter as a suspect embodiment of power. They indeed committed an abuse of power by "granting themselves" stock-options, a lexical choice suggesting they made themselves an untimely present out of their own initiative. Although it is not equivalent to stealing-we are in the domain of legality - the fact of granting oneself millions denotes the "impudence" that gives the article its title.

The syntactic and lexical choices that build up the polemical discourse are complemented by figures and clichés. The executives are ironically called "these little financial geniuses". "Petit génie", a cliché in spoken, familiar French, stands here in parallel and opposition to "grand chefs", the big bosses, another cliché borrowed from colloquial language. Referring to the register of familiar language adds to the virulence of the tone. "Quickly earned" millions refers to the pejorative cliché of "easy money" as opposed to money honestly earned by hard work. Eventually, it launches another oblique attack on capitalist modes of retribution, thus putting into question the whole system on a moral basis.

In this context, a major function is fulfilled by qualification, here understood in Perelman's argumentative meaning. The peculiar management of the preposition "de"- "of"-presents a specific trader, Kerviel, and a specific activity, speculating with subprimes, as characterizing and even defining the bank as a whole. Kerviel is a young trader famous for having lost a fortune to the bank through hazardous operations which escaped all controls. This formulation assimilates the unruly speculation of the trader, accused by the SG of having cheated it, with the bank who did not prevent the fraud. The mention of the subprimes obviously denounces the dubious and unfortunate speculations of the SG. The qualifications introduced by "the bank of" thus imply that the SG is guilty of excessive and unfortunate speculations that do not become a respectable enterprise. While using these qualifications, the text calls for the reader's identification through an elliptic and emphatic clause: "Yes, the bank of..." and a rhythm expressing violent indignation. Using a variety of discursive means, the polemical discourse succeeds in representing its target as abusing power, greedy, incompetent, and irresponsible on the verge of dishonesty. The discourse of blame - a classical form of epideictic rhetoricreinforces the communion of all the participants in the same 
values - here counter-values like sensible use of power, prudence, hard work, competence, responsibility, honesty.

If this linguistic analysis accounts for the polemical move, it does not, however, answer the question: what are the arguments developed to support the conclusion that the distribution of stock options is morally wrong and outrageous? We know that emotion is far from being cut off from reason (Walton 1992). The reader is entitled to look for a logically valid argument supporting the expressed moral judgment and even the feeling of indignation. Let us recall that moral feelings like indignation not only have a rational basis (Boudon 1994), but can be argued (Plantin 1998, Micheli 2008).

In this text, however, the formal arguments are not brought to the fore. They are rather hinted at through discursive elements fulfilling other functions in the sentence. This allusiveness does not prevent all possibility of reconstruction. Thus, the degree - though not the ultimate reason-of "unprecedented indignation" is justified by an argument embedded in the qualification of the US: "a country rather favorable to economical success". This is an argument a fortiori: If even a country where economical success is highly valued does not approve of some form of economical success, then nobody can approve of it. The implicit, and here most relevant, part of the argument is, however a topos of quantity (in the terminology of Perelman and Olbrechts-Tyteca) derived from the implicit comparison between the US and France: what applies to the more applies to the less, what outrages the US (which is the more) necessarily outrages France (which is the less). To be properly activated and to get its full impact, this utterance has to be read against the background of French culture with its resentment of big fortunes, its social imaginary feeding on the myth of the French Revolution and its ongoing criticism of American capitalism. Relying on these cultural premises, the underlying topos is to be reconstructed from the juxtaposition of the two symmetric utterances dealing with America and with France. This does not, of course, suffice to provide a reason for the moral judgment, nor does it explain the reasons justifying the powerful emotions invoked. A clearer case has to be made to "argue" indignation, a moral feeling based on a strong sense of injustice (the reward goes to somebody who does not deserve it).

Although present in the text, the tacit argument justifying the attack against the SG has also to be entirely reconstructed. To put it in enthymematic form: extra-benefits are distributed when an enterprise is thriving thanks to good financial management (implicit major premise), the bank has suffered severe losses as a result of hazardous speculation (alluded to by the qualification of the SG as the bank of Kerviel and stock-options), thus stockoptions should not be distributed in this bank (implicit conclusion). 
The enthymeme, if it still is one, appears as an almost entirely missing syllogism. The same goes for the just retribution of top executives: stock-options should be a reward for people who make benefits for the enterprise, the executives lost the enterprise's money, thus they are not entitled to stock-options. Rather than expressed, this argument is obliquely suggested by the ironic qualification "these little financial geniuses", an antiphrasis disqualifying the executives on the basis of their incompetence. It is also alluded to by the mention of the name of Kerviel, the SG's trader responsible for having speculated and lost colossal sums. While the minor premise (the executive of the SG lost their enterprise's money) can be reconstructed through these two allusions, the major premise is unexpressed and the conclusion only indirectly touched upon: the scandal of a stock options' distribution foregrounds the conclusion of what follows, without formulating it in so many words (the executives who lost their enterprise's money are not entitled to stock options).

A last implicit but capital link to formal arguments has to be clarified. Although it might look obvious, this point is rarely, to my knowledge, taken into account by argumentative analysis. Current interdiscourse includes not only recurring themes and phraseology, but also clusters of arguments. In a polemic, both parties advance arguments that progressively become familiar to the adversary as well as to the third party, as they are repeated over and over under various guises (or sometimes in the same formulations). Any new polemical discourse dealing with a debated social problem necessarily draws on this "script", or arguments' reservoir. Thus absent or only hinted at, arguments remain present as they can be recomposed with the help of elements stocked in the collective memory. Such a pattern of argumentation is frequent in polemical as well as in ordinary discourse. The way the speaker draws on the arguments' reservoir and loosely uses familiar clusters of arguments allows him to accommodate his own purposes. When he modulates them with pathos or evokes them in a fragmentary way, dissimulating formal patterns of arguments, it does not mean that no reasoning underlies his discourse. In this specific case, the idea that in a financially fragile enterprise, top executives should not lavish upon themselves large sums of money is largely circulated. So is the argument that by distributing stock-options to a bailed-out enterprise, top executives are exploiting the government and the tax payer; that the very people who lost the enterprise's money should not be rewarded by it; that patrons cannot get millions while workers are dismissed and condemned to unemployment, etc. All these claims, elaborated in the form of arguments closely linked to each other, circulate in the interdiscourse and are in the background of any new polemical discourse on the topic. They provide it with a global rationale on which it tacitly or openly rests. 
It is however important to emphasize that the choice to present arguments in oblique and dissimulated ways is in itself significant. In this case, the writer does not bother to argue about what he considers widely shared and self-evident. As has often been remarked upon, to provide reasons is to admit that the case can be controversial. Merely hinting at data that are an integral part of the argument allows for strong assertions. It leaves the way open to pathos and blocks possible objections and attempts at refutation. It thus helps the writer to present his opinion as consensual. As I already pointed out, the journalist here uses strong, very loosely argued assertions as a basis for an injunction calling on the executives' association (the Medef) and the French government for deeper involvement. From this perspective, it appears that to reconstruct the text as a mere series of arguments goes against its own argumentative logic, erases all the verbal means building up an attempt at persuasion and does not account for the way polemical discourse actually works.

Two main points have to be emphasized at this stage: (1) Argumentation can do without formal patterns of argument and be embedded in fluid discursive formulations suited to the logic of a specific argumentative mode or to a genre of discourse and, conversely, (2) formal patterns of arguments can be reconstructed from verbal constellations even when the discourse does not care to disclose them. The selected example has shown the gains and losses of translating actual discourse into argument. Conversely, it displays the problems faced by discourse analysis when it refuses to conform to any pattern of arguments. In the first case, we stick to formal arguments and thus lose all that goes beyond abstract schemes, e.g. the main body of the exchange and its intended impact. Obsessed by the rational, we do not perceive the verbal coconstruction of the reasonable. In the second case, we pay no attention whatsoever to patterns of arguments and thus lose underlying modes of reasoning contributing to the modeling of opinions and attitudes. Moreover, we cannot see how the peculiar treatment of arguments, the way they are scattered, dismembered, deconstructed and often indirectly reconstructed in the text, is in itself meaningful.

\section{Conclusion}

Focusing on the socio-discursive nature of argumentation, this approach analyzes how verbal exchanges co-construct ways of seeing, interpreting and experiencing the surrounding world, thus trying to reach an agreement on the reasonable or to deal polemically with deep disagreement. The theory of argumentation in discourse attempts at reconciling reconstruction of the formal 
arguments underlying the text with an exploration of the manifold, and sometimes subtle ways in which arguments are inscribed into the fabric of the text and verbally elaborated. Analysis of discourse is thus included in argumentation theory; reciprocally, analysis of logos, with its schemes of reasoning, is included in linguistic investigation. These complex and problematic interrelations are at the heart of a cross-disciplinary work based on a thorough examination of actual texts and corpora. From this perspective, philosophical questioning on the nature, functions and functioning of argument appears as intrinsically linked to linguistic questioning on discourse in its socio-institutional dimensions. In other words, a dialogue is established between disciplines like informal logic and discourse analysis.

On a second level, argumentation in discourse aspires at bridging the gap between argumentation theory and rhetorical criticism. Although both are made of a variety of trends and cannot be viewed monolithically, the first puts the emphasis on argument and reasoning in themselves, while the second sees argumentative discourse as situated and framed by an exchange between speaker and audience. Moreover, the first mainly examines logos in terms of validity (pathos, when addressed, is also measured in terms of validity), while the second stresses the central importance of ethos and pathos. From this perspective, argumentation in discourse is quite close to rhetorical criticism as practiced by rhetoricians like Michael Leff (2009), emphasizing the intrinsic inter-relation between text and context, the importance of the partners engaged in the exchange, the crucial role of ethos and doxa, the practice of close-reading, etc. However, argumentation in discourse aspires at articulating rhetoric and argumentation theory through an in-depth investigation of discourse. It thus presents a particular version of contemporary attempts to be found in other forms - for instance, in the current developments of pragma-dialectics (based on pragmatics and developing a rhetorical conception of "strategic maneuvering" as complementing dialectics) (van Eemeren 2009); in much current research developed today by rhetoricians and argumentation theorists who meet at common conferences and publish in the same journals; and in the insightful framework of the "rhetorical criticism" built by Christopher Tindale (2004), drawing on Perelman and Bakhtin, and close in many respects to my own work.

Last but not least, argumentation in discourse illuminates the social and institutional constraints put on the verbal exchange by the rules of the genre and of the field. It shows how the speaker's discourse necessarily echoes the discourse of the other and the rumor of the time. By showing the constitutive nature of interdiscourse as well as of cultural norms and institutional constituents, it promotes a conception of the speaking subject quite 
different from those developed by argumentation theories and traditional rhetoric. If this perspective puts into question the agency of the speaker, it is not to dismiss it, but rather tries to re-elaborate it in an interactional framework where the speaker is both determined by numerous factors, and bound in the limits of these constraints to exert his capacity of choice, if not to adopt a stance. The notions of responsibility and of accountability are thus preserved in a framework where the weight of cultural and socioinstitutional rules is acknowledged.

As a whole, the approach advocated by "argumentation in discourse" is an attempt at revisiting the complex relationships between argumentation theories, rhetoric and discourse analysis, and at solving, at least partially, the tensions and contradictions keeping them apart. Hopefully, it goes in its own way along the lines of the recent opening of informal logic to new disciplines as expressed in the paper of Ralph H. Johnson at the Argument Cultures Conference, and in the very subject chosen for this 2009 conference.

\section{References}

Amossy, R. (2006). L'Argumentation dans le discours, $2^{\text {nd }}$ ed. Paris: Colin.

Amossy, R. 2005. "The argumentative dimension of discourse". In: F.H. van Eemeren \& P. Houtlosser (eds.), Practices of Argumentation, pp. 87-98. Amsterdam: John Benjamins Publishing Company.

Amossy, R. (2009). "The New Rhetoric's Inheritance. Argumentation and Discourse Analysis", Argumentation 23:2. Also in Perelman and Beyond. Current Issues in Argumentation Studies, Amossy, R., Koren, R. and Yanoshevsky Galia (eds).

Anscombre, J.-C. and Ducrot, O. (1988). L'Argumentation dans la langue. Liège: Mardaga.

Bakhtin, M. (1986) Speech Genres and Other Late Essays. Trans. by Vern W. McGee. Austin, TX: University of Texas Press .

Benveniste, E. (1971). Problems in General Linguistics. Trans. M. E Meek. Coral Gables, FL: University of Miami Press.

Boudon, R. 1994. "La logique des sentiments moraux", L’Année sociologique 44, 19-51.

Bourdieu, P. (1991). Language and symbolic power. Cambridge : Polity Press.

Charaudeau, P. \& Maingueneau, D. (éds.). 2002. Dictionnaire d'analyse du discours. Paris: Le Seuil.

Ducrot, O. (2004). "Argumentation linguistique et argumentation rhétorique", in Doury, M. and Moirand, S. (eds). L'argumentation aujourd'hui. Positions théoriques en 
confrontation, pp. 17-33. Paris: Presses de la Sorbonne Nouvelle.

Eemeren, van F.H.(ed). (2009). Examining Argumentation in Context. Fifteen Studies on Strategic Maneuvering. Amsterdam/Philadephia: Benjamins.

Johnson, R.H., forthcoming, "Revisiting the logical/dialectical/rhetorical triumvirate", Proceedings of the 2009 OSSA conference "Argument Cultures."

Johnstone, B. (2008). Discourse Analysis, $2^{\text {nd }}$ ed. Oxford: Blackwell.

Jonhstone, B. and Eisenhart, C. (2008). Rhetoric in detail. Discourse analyses of rhetorical talk and text. Amsterdam/Philadephia: Benjamins.

Kerbrat-Orecchioni, C. (1980). "La polémique et ses définitions", in Gelas, N. and Kerbrat-Orecchioni (éds), Le discours polémique, pp. 3-40. Lyon: PUL.

Leff, M. (2009). "Perelman, Ad Hominem Argument, and Rhetorical Ethos", Argumentation 23: 2. Also in Perelman and Beyond. Current Issues in Argumentation Studies, Amossy, R., Koren, R. and Yanoshevsky Galia (eds).

Maingueneau, D. and Angermüller, J. (2007). "Discourse Analysis in France. A Conversation". Forum Qualitative Sozialforschung / Forum: Qualitative Social Research, 8(2), Art. 21, http://nbnresolving.de/urn:nbn:de:0114-fqs0702218

Micheli, R. (2008 ). "La construction argumentative des émotions: pitié et indignation dans le débat parlementaire de 1908 sur l'abolition de la peine de mort", in Rinn, M. (éd.), Emotions et discours. L'usage des passions dans la langue, pp. 127-141. Rennes: Presses Universitaires de Rennes.

Perelman, Ch. and Olbrechts-Tyteca, L. (1969). The New Rhetoric. A Treatise on Argumentation. (trans. By J. Wilinson and P. Weaver). Notre-Dame/London: University of Notre-Dame Press $\left[1^{\text {st }}\right.$ ed. in French, Paris: Presses Universitaires de France, 1958].

Perelman, Ch. (1979). "The rational and the reasonable" in Ch. Perelman, The New Rhetoric and the Humanities. Essays on Rhetoric and its Applications, pp. 117-123. Dordrecht/Boston/London: D. Reidel,

Plantin, C. (1998). "Les raisons des émotions", in Bondi, M. (éd.). Forms od argumentative discourse / Per un'analisi linguistica dell'argomentare), pp. 3-50. Bologne: CLUEB.

Tindale, Ch.W. (2004). Rhetorical Argumentation. Principles of Theory and Practice. London: Sage.

Viala, A. (1998). "L'éloquence galante. Une problématique de l'adhésion" in Amossy, R. (ed), Images de soi dans le discours. Genève : Delachaux et Niestlé.

Walton, D. (1992). The Place of Emotion in Argument. University Park, PA: The Pennsylvania State University Press. 